\title{
Floresta e clima
}

\author{
Eneas Salati * \\ Maria de Nazaré Góes Ribeiro *
}

Para uma compreensão clara do problema ecológico que atravessamos, é necessário ter-se em mente as relações fundamentais entre a atmosfera, a hidrosfera, a litosfera e a biosfera. Neste trabalho, analisam-se em seus aspectos gerais, os problemas da hidrosfera, com particular ênfase à problemática da ecologia da Bacia Amazônica. Em seguida, chama-se atenção para possíveis alterações do clima e do regime hídrico da região, em função do desmatamento.

A atmosfera, tênue camada gasosa que envolve a Terra, não possuiu sempre a composição que ora se conhece. Durante os processos de diferenciação e solidificação da crosta terrestre, que se iniciou há uns cinco biIhões de anos, os gases liberados incluindo vapor d'água, deram origem a uma atmosfera primitiva. Ainda hoje, através do prolongamento desse processo, que não terminou, os vulcões ativos continuam liberando gases que se incorporam à atmosfera. A força gravitacional, determinada pela massa do planeta e os processos físico-químicos acabaram por determinar algumas das características da atmosfera. No entanto, a presença de um dos componentes, o oxigênio no atual nivel, só foi possível dada a ação contínua e constante de organismos capazes de realizar fotossíntese (Berkner \& Marshall, 1965).

A produção de oxigênio, por este processo, teve início, há pelo menos 2,7 bilhões de anos, aumentando sua concentração de próximo a zero até $\bar{a}$ atual de aproximadamente $21 \%$, através de uma interação contínua e constante de organismos vegetais com o meio ambiente.

Embora atualmente a composição média dos componentes da atmosfera permaneça constante, existe uma recirculação ativa e constante de, praticamente, todos os gases. 0 tempo médio de residência dos gases na atmosfera é muito pequeno, comparado aos tempos geológicos, sendo da ordem de trezentos anos para $0 \mathrm{CO}_{2}$, dois mil anos para o oxigênio e cerca de dois milhões de anos para o nitrogênio. Por outro lado, o vapor d'água tem um tempo de residência muito baixo, em particular na Bacia Amazônica, de aproximadamente três meses. É importante notar que alterações nos componentes dos ciclos desses gases poderão introduzir modificações ecológicas.

Através de um lento processo de interações, as forças da natureza definem os ecossistemas naturais caracterizando o solo, o clima e as espécies dos reinos vegetal e animal, atingindo o ecossistema um estado de equilíbrio dinâmico e aí permanecendo até que novas alterações sejam introduzidas. Nas oscilações de equilíbrio dos ecossistemas, tem que levar-se em consideração, as decorrentes de fenômenos naturais, que ocorrem e que determinam grandes modificações climáticas. Como conseqüência das variações do clima, adaptações ocorrem na flora e na fauna, atingindo a biosfera diferentes condições de equilíbrio.

$\mathrm{Na}$ análise do equilíbrio dinâmico do sistema ecológico, é necessário identificarem-se as causas e os efeitos, ou em outras palavras, precisa-se conhecer e quantificar os fatores que determinam e que acabam por definir as características dos ecossistemas. O estado de equilíbrio varia, no tempo, pelas oscilações dos fatores que o condicionam. São bem conhecidas as oscilações climáticas de diversas regiões durante as glaciações, cujas marcas estão bem caracterizadas e bem estudadas, especialmente na Europa e América do Norte. Sabe-se que na bacia amazônica ocorreram modificações ecológicas e, há setecentos anos, algumas regiões apresentavam características de semi-aridez (Absy, 1979). O que ocorre é que por motivos ainda não bem definidos, mas relacionados com a atividade solar, a tempe. ratura média do planeta tem variado através 
do tempo e as camadas de gelo que hoje cobrem as calotas polares, em alguns períodos, se expandiram cobrindo grande parte da Europa, Ásia, América do Norte e América do Sul. Essas oscîlações determinadas pelos fatores naturais, foram sentidas já dentro do tempo histórico, ou seja, nos últimos milênios.

Hoje, com o crescimento exponencial da população, além das oscilações naturais, são introduzidas pela atividade humana, modificações cada vez maiores, em alguns casos, incontroláveis.

O equilibrio natural atingido pelos grandes ecossistemas das Américas permaneceu inalterado até o ano de 1.500 , sendo perturbado pela ação do homem, a partir da chegada dos primeiros exploradores. $\mathrm{Na}$ Europa, na Ásia e, especialmente, no Oriente Médio, as modificações introduzidas pelas civilizações datam de milênios.

Na bacia amazônica, o equilíbrio hídrico ainda não sofreu grandes perturbações através da atividade humana. $E$, procurando quantificar os componentes do balanço hídrico $\mathrm{e}$ outros aspectos dos estudos do clima, foram analisados milhares de dados acumulados através de diversos organismos. O trabalho envolveu análises e dados da superfície e da atmosfera superior. As conclusões científicas estão publicadas em teses de mestrado, doutoramento e em artigos e revistas científicas ou ainda em forma de relatórios preliminares (Brasil. Ministério da Agricultura, 1969; Decico et al., 1977; Marques, 1976; Marques et al., 1977, 1978 e 1979b; Ribeiro, 1976 e 1977; Ribeiro \& Villa Nova, 1979).

Para muitos, a cobertura florestal de uma região é, de certa forma, uma conseqüência do clima e do solo. Esta afirmação, no que diz respeito ao balanço hídrico é, em parte, verdadeira para bacias hidrográficas em que a recirculação da água dentro da própria bacia é pequena ou desprezível, quando comparada aos outros componentes do ciclo hidrológico. Esta situação ocorre em regiões subtropicais onde o desmatamento não alterou substancialmente o clima. Porém, mesmo neste caso, é necessário ressaltar que a quantificação da influência do desmatamento sobre o ciclo da água, só poderia ter sido feita se os parâme- tros do balanço hídrico, fossem conhecidos antes das alterações. Infelizmente, só após a colonização intensiva, com a destruição das grandes florestas do planeta, é que o homem iniciou as medidas para conhecer os parâmetros do clima.

Do ponto de vista específico da bacia amazônica, tem-se, em primeiro lugar, que salientar a geomorfologia e a localização da região cortada pelo Equador. A "planície" central da bacia amazônica tem por bordaduras laterais o planalto das Guianas e o planalto Central Brasileiro e a Oeste é bloqueada pela cordiIheira dos Andes. Dessa forma os ventos alísios que introduzem na região o vapor d'água proveniente do oceano Atlântico (Fig. 1; Marques et al., 1979a), tem barreiras naturais especialmente no semicírculo andino, que impõe uma precipitação do vapor d'água através de chuva ou de neves. Assim as características geomorfológicas e a localização da região interceptando os ventos quentes e úmidos da circulação geral da atmosfera e a convergência intertropical, levam a uma resultante que tende a determinar um clima quente e úmido, possibilitando o desenvolvimento de uma floresta equatorial.

O desenvolvimento do ecossistema amazônico e o seu equilibrio atual determinam o balanço hídrico que atualmente conhecemos. A origem primária do vapor d'água é o oceano Atlântico, no entanto, a divergência do fluxo do vapor d'água indica que aproximadamente $50 \%$ da precipitação atual é proveniente dessá fonte primária de vapor. Assim, as plantas que embora originalmente se desenvolveram graças as condições primárias do ecossistema em evolução, hoje são partes integrantes e fundamentais para o equilíbrio estabelecido, fornecendo através da evapotranspiração os outros $50 \%$ do vapor d'água necessário para gerar o atual nível de precipitação (Fig. 2; Sa. lati et al., 1978); (Dall'Olio et al., 1979; Mar ques et al.; 1980a, b; Molion, 1975; Salati et al., 1979).

O amadurecimento do ecossistema atual foi atingido através de equilíbrios sucessivos e de experiências seletivas progressivas, havendo uma interação constante e dinâmica entre a biosfera e a atmosfera e seria errôneo 
pensar-se que as condições climáticas atuais eram exatamente idênticas àquelas no início da evolução do sistema amazônico.

Embora não se tenham ainda dados que permitam prever com precisão as conseqüências da substituição ou simples destruição da cobertura vegetal da região amazônica, podese porém, inferir algumas das alterações, que sobrevirão, se essas substituições forem de natureza radical :

a) $\mathrm{O}$ desflorestamento reduzirá o tempo de permanência da água na bacia, por diminuir a permeabilidade do solo e conseqüente. mente o seu armazenamento em reservatórios subterrâneos. A redução do período de trânsito das águas determinará inundações mais intensas durante os períodos de chuvas, enquan- to que a diminuição dos reservatórios subter. râneos, reduzirá a vazão dos rios nos períodos de seca (Salati, 1978);

b) Como já se evidenciou, experimentalmente, $50 \%$ da precipitação da região amazônica é proveniente da evapotranspiração da floresta. Através deste processo, a floresta aumenta o tempo de permanência da água no sistema, devolvendo para a atmosfera na forma de vapor, a água presente no solo. Uma outra cobertura, cuja evapotranspiração não substitua a inicial da região, determinará uma menor disponibilidade de vapor na atmosfera e, em conseqüência, uma redução na precipitação, especialmente nos períodos mais secos. Deve esperar-se, pois que, no caso de substituição de florestas por pastagens, ou

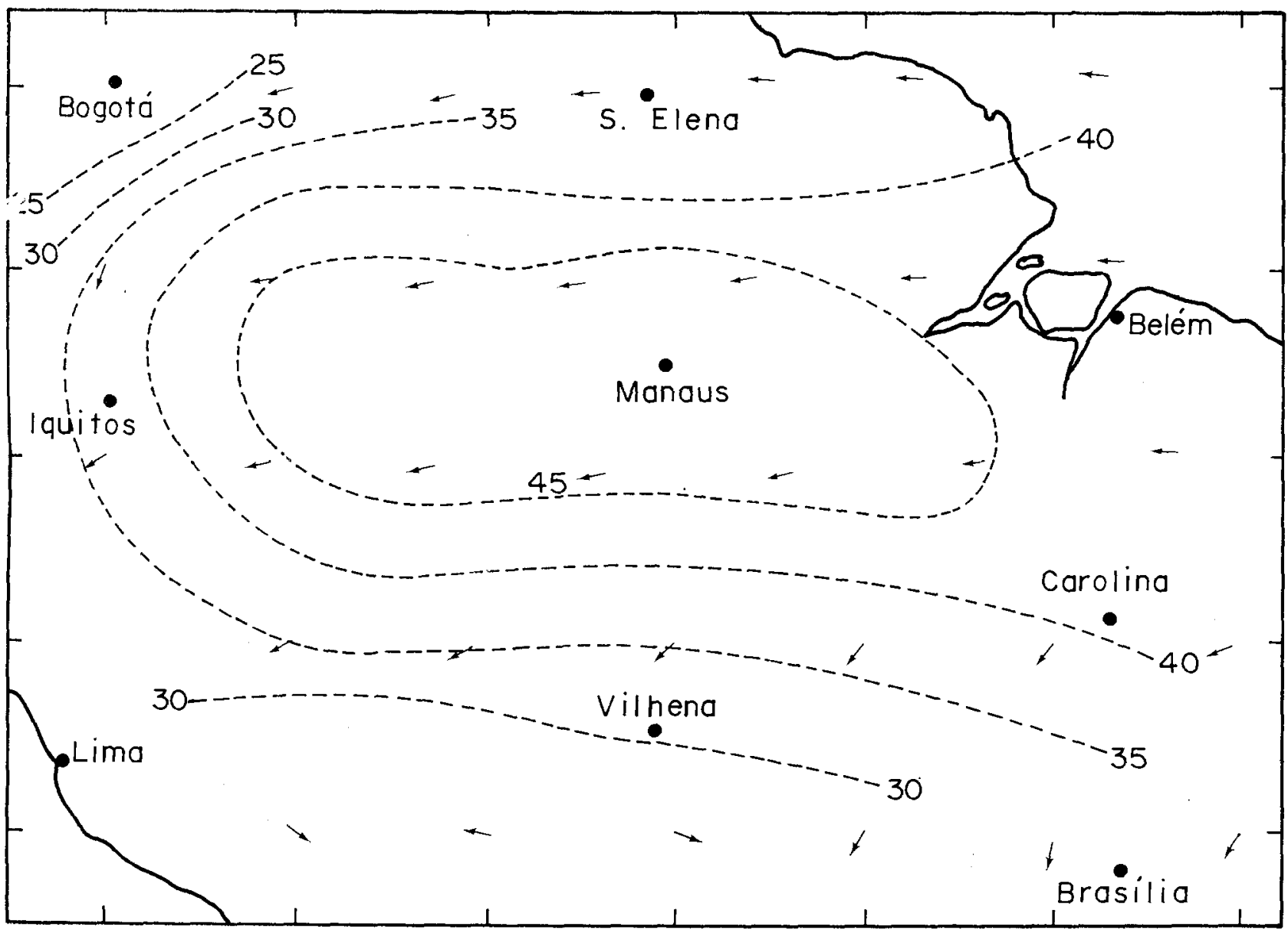

Fig. 1 - Fluxo de vapor d'água. Média do período $1972 / 1975$, obtida para as quadrículas de $5^{\circ}$ de latitude por $5^{\circ}$ de longitude. Valores para dezembro. Linhas tracejadas: água precipitável, em $\mathrm{mm} \leftarrow 1 \mathrm{~cm}=2.000$ $g_{v} \mathrm{~cm} . \mathrm{s}$ (Marques et al., 1979a). 


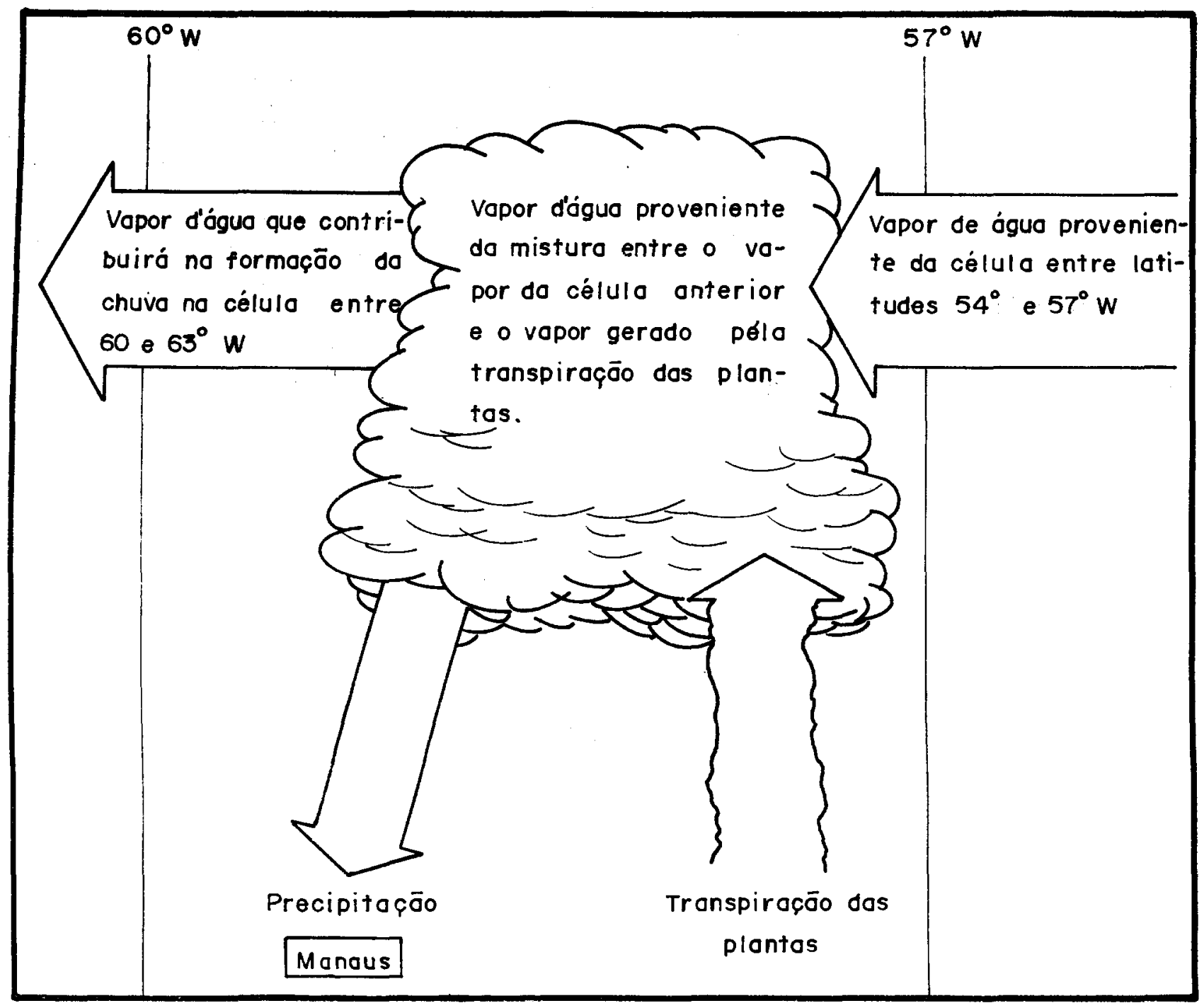

Fig. 2 - Esquema geral para explicar a formação das chuvas na Amazônia a partir de duas fontes de vapor: o oceano Atlântico e floresta. A região foi dividida em faixas de $3^{\circ}$ de longitude. 0 esquema desta figura indica a cidade de Manaus. (Salati et al., 1978).

culturas anuais em grande extensão da bacia amazônica, o clima sofra uma modificação no sentido de ter um período seco prolongado. melhor definido com um "deficit" de água no solo;

c) É importante salientar que uma redução da precipitação de 10 a $20 \%$ já será suficiente para induzir profundas modificações no atual ecossistema. Haverá modificações sucessivas na flora e na fauna, até ser atingido um novo equilíbrio ecológico. Tudo indica que a realimentação é positiva e os equilíbrios dinâmicos sucessivos terão curta duração. É impossível, no nível do conhecimento atual, prever as características do equilibrio final; d) A região amazônica é, no momento, uma fonte de vapor d'água para as regiões circunvizinhas. Existem evidências de que há um fluxo de vapor d'água do norte para o sul, durante o ano todo, na região. Assim, é provável que uma parte do vapor d'água que origina as chuvas da região central da América do Sul seja proveniente da bacia amazônica. Espera-se, pois que, haja modificações no ciclo d'água, ou no total da água disponível na bacia platina e mesmo no planalto central brasileiro. A interdependência entre as massas de ar da bacia amazônica e a do Orinoco é totalmente desconhecida. Nestes termos, é necessário salientar que o potencial hidrelétrico es- 
timado para o Brasil, tendo em vista as precipitações da região do Planalto Central Brasileiro que alimentam as cabeceiras das principais bacias hidrográficas, poderá ficar alterado. Pela simples dúvida, e no nosso caso existe uma forte evidência desta modificação, medidas especiais de precauções devem ser tomadas quanto à política florestal a ser adotada.

A fim de que o clima não viesse a ser perturbado ou para que as modificações introduzidas fossem pequenas, seria necessário que a cobertura vegetal que substituísse a floresta tivesse o mesmo comportamento da floresta, no que concerne aos balanços da energia e da água, bem como, na estrutura do perfil de vento.

A cobertura do solo por plantas de pequeno porte (cana-de-açúcar e pastagem) poderá ser equivalente à da cobertura da floresta, se forem seguidas as seguintes condições -

- Cobertura total da área, que deverá permanecer sempre verde a fim de não modificar o albedo da superficie;

- Ter o mesmo comportamento que a floresta com respeito ao tempo de residência da água no ecossistema. Esta condição poderá ser atingida com a utilização de técnicas de conservação do solo. Não podem existir perturbações ou descontinuidade no ciclo vegetativo a fim de que o consumo da água seja sempre constante e o sistema radicular deverá estar em constante atividade.

Mesmo atingidas as duas condições acima apontadas, o sistema de plantas de porte uniforme (cana-de-açúcar e pastagem) introduzirá modificações na dinâmica da atmosfera pela modificação da rugosidade da superfície, que altera o perfil do vento. A mudança deste parâmetro altera completamente a interface planta-atmosfera modificando o balanço em escala microclimática. Essa alteração estendida a grandes áreas introduzirá modificações na dinâmica geral da atmosfera para considerações meso ou macroclimáticas.

As análises dos dados de vento, desde o nível do solo até 5.500 metros, de 5 anos de observações, demonstram que os ventos são mais intensos em Belém, diminuindo à medida que penetram no continente. Já em Manaus, as velocidades são bem menores (Mar- ques, 1978). Por outro lado, a umidade do ar é menor em Belém aumentando à medida que se penetra no continente. Estes fatos demonstram a influência do tipo de cobertura do solo e a contribuição do continente (floresta) na determinação das características meteorológicas da atmosfera para a região. Por outro lado, já existem áreas da região amazônica, nas quais o comportamento diferencial de áreas com pastagem e com florestas podem ser observadas. Um exemplo típico é a ilha de Marajó. As áreas cobertas com florestas possuem uma precipitação melhor distribuída durante o ano, com a precipitação mínima mensal de ordem de $80 \mathrm{~mm}$. Já nas áreas cobertas com pastagem, a precipitação atinge ZERO no período de estiagem. Assim a pastagem natural da ilha não consegue comportar-se da mesma forma que as florestas, no que diz respeito ao ciclo da precipitação. O total de precipitação das duas áreas é praticamente o mesmo. Observa-se ainda nesta ilha, que as oscilações diárias da temperatura são maiores nas áreas de pastagem indicando menor disponibilidade de água na atmosfera. Observase também, que os cúmulos de formação local são menores e têm as suas bases a maior altitude nas áreas de pastagem do que nas áreas de floresta;

e) A energia solar que incide na região

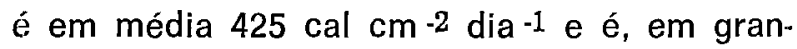
de parte, utilizada no trabalho de evaporação das águas, através da transpiração das plantas (Villa Nova et al., 1976). Estima-se que 50 a $60 \%$ de energia solar seja utilizada nesse processo. No caso de desflorestamento, em grande escala, o balanço de energia será alterado. Uma grande parte de energia que hoje é utilizada pelas plantas para transpirar, será utilizada no processo de aquecimento do solo e do ar. Nas áreas com cobertura descontínua, observa-se que uma parcela de energia é utilizada no aquecimento do ar (a radiação solar aquece o solo e este aquece a atmosfera) sendo a temperatura do ar, nesse tipo de ecossistema, maior que a temperatura das áreas florestadas. Medidas contínuas, em áreas de campinas e de florestas, perto de Manaus, demonstram este fato (Ribeiro \& Santos, 1975). Até o momento, não existe possibilidades de prever-se quais as modificações, 
na dinâmica da atmosfera da região amazônica, como um todo, e suas influências sobre as regiões circunvizinhas;

f) Sabe-se que as regiões tropicais absorvem mais radiação solar do que perdem por emissão de ondas longas. Há, portanto, um saldo no balanço de radiação nos trópicos. Nas latitudes mais altas, incluindo as regiões polares a situação é contrária. Como, a longo tempo, a temperatura média do planeta não se altera, conclui-se que uma das funções bá. sicas da circulação atmosférica é transportar calor dos trópicos para os polos (Nobre, 1979; informação pessoal). Uma das circulações que desempenham tal função é chamada células de Hadley. As células de Hadley dependem, fundamentalmente, da quantidade de vapor d'água que é transportado para os altos níveis atmosféricos e que ao condensar liberam calor to calor solar utilizado na evapotranspiração da água, na superfície, é liberado a camadas mais altas, quando o vapor d'água condensa). Este calor funciona como uma fonte de energia para a circulação geral da atmosfera; assim, sobre os continentes a evapotranspiração é atuante na dinâmica deste sistema. No evento de drástico desmatamento, na região amazônica, os padrões de evapotranspiraçäo irão alterar-se, muito provavelmente no sentido de uma diminuição. Tal mudança não só irá acarretar sensíveis modificações no micro e mesoclima, como já foi exposto anteriormente, mas poderá atingir também o clima global através da alteração do balanço de energia de circulação de Hadley. Este balanço de energia seria alterado através de dois mecanismos principais : em primeiro lugar a evapotranspiração, diminuindo, irá provocar menor liberação do calor latente de condensação nos altos niveis e, em segundo lugar, a vegetação que substituir a floresta terá albedo diferente e isto atingirá o balanço de energia da superfície;

g) Quanto aos ciclos que envolvem o oxigênio e o gás carbônico, há uma falta de informação quando se afirma que a floresta amazônica é o pulmão do mundo, sendo uma fonte importante de oxigênio para a atmosfera. Realmente, a floresta amazônica encontra-se em um estado denominado de "climax" pelos ecologistas, o qual é caracterizado pelo aproveitamento total da energia fixada pelas plan. tas, através de interações da cadeia alimentar. Assim, o oxigênio, que é liberado pela atividade fotossintética, é utilizado pelas próprias plantas e pelos demais organismos vivos do ecossistema. Como, ao longc do tempo, não existe mais acúmulo de matéria orgânica, pode afirmar-se que numa média anual, não existe produção líquida de oxigênio nos tipos de florestas encontradas na Amazônia. A produção líquida de oxigênio seria representada pela matéria orgânica que sai da região através dos rios, tais como os ácidos húmicos existentes nos rios de águas negras $\mathrm{e}, \mathrm{cm}$ bora não exista ainda uma quantificação, sabese que representa uma pequena parcela da produção anual de matéria orgânica da floresta.

É importante salientar, no entanto, que as florestas representam um reservatório de carbono, ou seja, na floresta o carbono está fixado em compostos orgânicos. No atual equilíbrio do planeta, o carbono fixado pelas plantas é aproximadamente três vezes maior que o existente na atmosfera na forma de gás carbônico.

A pressão parcial do $\mathrm{CO}_{2}$ na atmosfera é determinada pela interação deste gás com o oceano que libera e absorve $\mathrm{CO}_{2}$ numa velocidade muito grande (Cloud \& Gibor, 1974). Em apenas algumas dezenas de anos, todo $\mathrm{O} \mathrm{CO}_{2}$ da atmosfera é renovado através deste dinâmico processo de interação por troca molecular com o oceano. Essa situação levava, até recentemente, a uma concentração constante de $290 \mathrm{ppm}$ de $\mathrm{CO}_{2}$ na atmosfera. No entanto, a partir do início deste século, o equilíbrio deste processo foi rompido pela atividade humana $e$ esta é a primeira grande evidência, de que 0 homem pode realmente alterar o equilíbrio ecológico do planeta e não somente de uma pequena região. Observações pormenorizadas atuais, indicam que o gás carbônico da atmosfera vem aumentando de maneira contínua a uma taxa de, aproximadamente 1 parte por mithão por ano (Fig. 3; Woodwell et al., 1978) . As causas deste aumento são principalmente a queima dos combustíveis fósseis e a destruição das florestas. $\mathrm{O} \mathrm{CO}_{2}$ atmosférico es- 


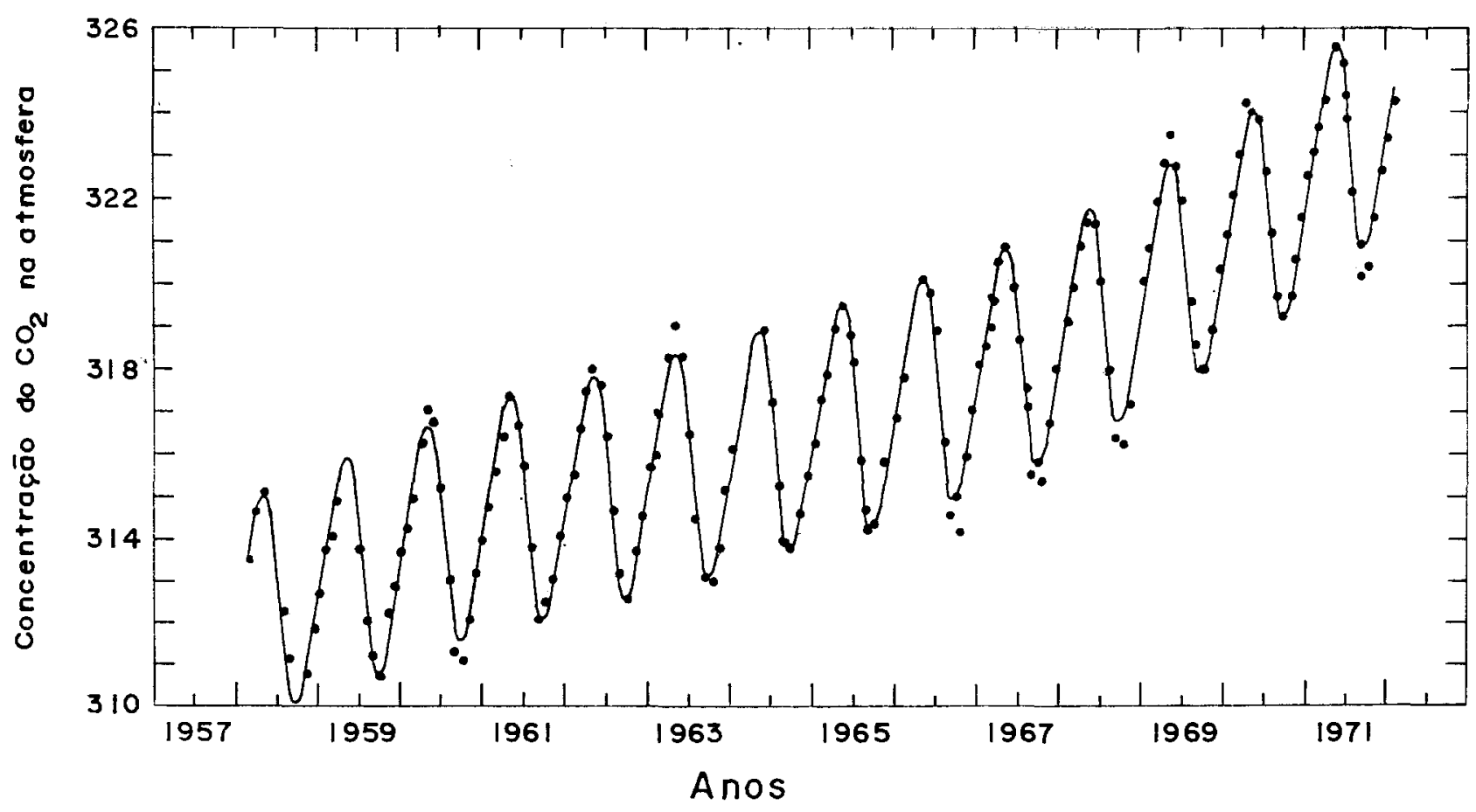

Fig. 3 - Variações a longo prazo no conteúdo de $\mathrm{CO}_{2}$ do ar no Observatório de Mauna Loa (Eckdahl \& Keeling apud Woodwell et al., 1978).

tá intimamente ligado ao mecanismo do balanço de energia do planeta e a floresta amazônica representa aproximadamente $20 \%$ do reservatório de carbono da biomassa do planeta (Salati, 1979].

\section{Bibliografia}

AESY, M. L.

1979 - A palynological study of Holocene sediments in the Amazon basin. Tese, Univ. Amsterdam.

Berkner, L. V. \& Marshall, L. C.

1965 - On the origin and rise of oxygen concentration in the Earth's Atmosphere. Journal of the Atmospheric Sciences, 22 (3): 225261.

BRASIL. Ministério da Agricultura

1969 - Atlas Climatológico do Brasil. Rio de Ja. neiro.

Cloud, P. \& GiBor, A.

1974 - O ciclo do oxigênio. A Biosfera; textos do Scientific American; tradução do prof. Luiz Roberto Tommasi. São Paulo, p. 65-75.

Lall'Ollo, A; Salati, E; Azevedo, C. T. de \& Matsui, E.

1979 - Modelo de fracionamento isotópico da água na Bacia Amazônica. Acta Amazonica, 9 (4): 675-687.
Dfcico, A.; Santos, H.M.; Ribeiro, M.N.G.

\& Salati, E.

1977 - Estudos Climatológicos da Reserva Florestal Ducke, Manaus-Am. I. Geotemperaturas. Acta Amazonica, 7 (4): 485-494.

MARQues, J.

1976 - "Contribuição ao estudo hidrológico da Bacia Amazônica". Tese de Mestrado, ESALO. Piracicaba, São Paulo.

1978 - A transferência horizontal de vapor d'água na troposfera e a hidrologia da bacia amazônica. Tese de Doutor, ESALQ., Piracicaba, Săo Paulo.

Marques, J.; Salati, E.; Santos, J. M. dos

1980a - A divergência do campo do fluxo de vapor d'água $e$ as chuvas na região amaziònica. Acta Amazonica, 10 (1): (aceito para publicação).

1980b-Cálculo de evapotranspiração real na Bacia Amazônica através do método aerológico. Acta Amazonica, 10 (1): (aceito para publicação).

Marques, J.; Santos, J. M. dos \& Salatt, E.

1978 - Considerações sobre os ventos na Região Amazônica. Acta Amazonica, 8 (1): 110-113.

1979a- O campo do fluxo de vapor d'água atmosférico sobre a região Amazônica. Acta Amszonica, 9 (4): 701-713.

$1979 b-0$ armazenamentto atmosférico de vapor d'água sobre a região Amazônica. Acta Amazonica, 9 (4): 715-721. 
Marques, J.; Santos, J.M. dos; VIlla Nova, N.A. \& Salati, E.

1977 - Precipitable water and water vapor flux between Belém and Manaus. Acta Amazonica, 7 (3): 355-362.

Molion, L. C. B.

1975 - A climatonimic study of the energy and moisture fluxes of the Amazonas basin with considerations of deforestation effects. Tese de PhD, Universidade de WisconsinMadison. 133p.

Ribeiro, M. N. G.

1976 - Aspectos climatológicos de Manaus. Acta Amazonica, 6 (2): 229-233.

1977 - Anuário Meteorológico do INPA. Anos 1965 a 1977, Manaus, Am.

Ribeiro, M. N. G.; \& SANtos, A. dos

1975 - Observações microclimáticas no Ecossistema Campina Amazônica. Acta Amazonica, 5 (2): 183-189.

Ribeiro, M. N. G. \& Villa Nova, N. A.

1979 - Estudos Climatológicos da Reserva Florestal Ducke. Manaus. Am. III. Evapotranspiração. Acta Amazonica, 9 (2): 305-309.
SALATI, E.;

1978 - Influência do desmatamento no ciclo da água na Amazônia, Suplemento Cultural do Estado de São Paulo: (mimeografado).

1979 - Floresta Amazônica e a concentração de gás carbônico na atmosfera. Suplemento Cultural do Estado de São Paulo, 130.

Salati, E.; Dall'Olio, A.; Matsui, E. \& Gat, J. R.

1979 - Recycling of water in the Amazon Basin : An isotopic study. Water Resources Research: (no prelo).

Salati, E.; Marques, J. \& Molion, L. C. B.

1978 - Origem e distribuição das chuvas na Ama. zônia. Interciência, 3 (4): 200-206.

Villa Nova, N. A. Salati, E.; \& Matsui, E.

1976 - Estimativa da Evapotranspiração na Bacia Amazōnica. Acta Amazonica, 6 (2): 215-228.

WoOdwell, G. M.; WhitTaker, R. H.; Reiners, W. A.; Likens, G. E.; Delwiche, C. C.; \& BotkIN, D. B.

1978 - The Biota and the World Carbon Budget. The terrestrial biomass appears to be a net source of carbon dioxide for the atmosphere. Sclence, 199: 141-146. 